\title{
Prognostic Significance of Monocyte to High-density Lipoprotein Ratio in Patients With Coronary Chronic Total Occlusion
}

\author{
Muhammed Demir ${ }^{1}$, Mehmet Ozbek ${ }^{1}$, Adem Aktan ${ }^{2}$, Tuncay Güzel ${ }^{3}$, and Burhan Aslan ${ }^{3}$ \\ ${ }^{1}$ Dicle University Medical Faculty \\ ${ }^{2}$ Affiliation not available \\ ${ }^{3}$ Diyarbakir Gazi Yasargil Training and Research Hospital
}

April 27, 2021

\begin{abstract}
Objective: Development of chronic total occlusion (CTO) consists of multiple histological stages, with each stage containing different histopathological features. The monocyte to high-density lipoprotein ratio (MHR) is a useful marker of the degree of inflammatory response. The aim of this study was to investigate the relationship between MHR and long-term survival and mortality in CTO patients. Methods: The study included 493 CTO patients that were followed over a period of 73 months between January 2011 and December 2019. MHR was calculated from the venous blood samples taken from each patient immediately before routine coronary angiography. Results: The study included 493 patients comprising 353 (71.6\%) men and $140(28.4 \%)$ women with a mean age of $63.03 \pm 10.88$ years. Median follow-up period was 48 (interquartile range [IQR]: 26-73) months. Patients were divided into two groups: (I) MHR <17.68 ( $\mathrm{n}=278)$ and (II) MHR [?]17.68 (n=215). Long-term mortality was significantly higher in group II than in group I $(\mathrm{n}=70,32.6 \%$ vs. $\mathrm{n}=43,15.5 \%$; $<<0,001)$. On multivariate logistic regression analysis, MHR was found to be an independent predictor of long-term mortality (Odds Ratio [OR]: 1.089, 95\% Confidence Interval [CI]: 1.055-1.124, p<0,001). The Kaplan-Meier analysis showed lower survival rates in group II (MHR [?]17.68) than in group I (MHR <17.68) (75.223+-2.670 vs. 89.220+-2.102, p<0,001). Conclusion: MHR could be used as a practical universal biomarker of mortality and survival in CTO patients.
\end{abstract}

\section{Prognostic Significance of Monocyte to High-density Lipoprotein Ratio in Patients With Co- ronary Chronic Total Occlusion}

Objective: Monocyte to high-density lipoprotein ratio is a marker of inflammatory response. We investigate the relationship between MHR and mortality in CTO patients.

Methods: Study included 493 patients followed over a period of 73 months. Blood samples taken from patient before coronary angiography.

Results: Median follow-up was 48 months. Patients were divided into two groups: (I) MHR $<17.68$ (n=278) and (II) MHR [?]17.68 ( $\mathrm{n}=215)$. Mortality was significantly higher in group II than in group I (n=70 vs. $\mathrm{n}=43 ; \mathrm{p}<0,001$ ). MHR was found to be an predictor of mortality (OR: 1.089, 95\% [CI]: 1.055-1.124, $\mathrm{p}<0,001$ ). Kaplan-Meier showed lower survival rates in group II than in group I (75.223 \pm 2.670 vs. $89.220 \pm 2.102$, $\mathrm{p}<0,001)$.

Conclusion: MHR could be used as a biomarker of mortality in CTO patients

Key words: Chronic total occlusion, risk predictor, monocyte to high-density lipoprotein ratio, long-term mortality, inflammation

What's already known about this topic? 
The association of MHR as an inflammatory marker with atherosclerotic diseases, various heart diseases, various inflammatory diseases and some types of cancer has been demonstrated in clinical studies.

\section{What does this article add?}

We have shown that high MHR were significant and independent predictor of long-term mortality in patients with CTO.MHR is a practical biomarker that may be useful for long-term cardiac risk stratification in patients with coronary chronic total occlusion.

\section{Hosted file}

Prognostic Significance of Monocyte to High-density Lipoprotein Ratio in Patients With Coronary Chronic available at https://authorea.com/users/410353/articles/519750-prognostic-significance-ofmonocyte-to-high-density-lipoprotein-ratio-in-patients-with-coronary-chronic-totalocclusion

\section{Hosted file}

References.pdf available at https://authorea.com/users/410353/articles/519750-prognosticsignificance-of-monocyte-to-high-density-lipoprotein-ratio-in-patients-with-coronarychronic-total-occlusion

\section{Hosted file}

Table 1.pdf available at https://authorea.com/users/410353/articles/519750-prognosticsignificance-of-monocyte-to-high-density-lipoprotein-ratio-in-patients-with-coronarychronic-total-occlusion

\section{Hosted file}

Table 2.pdf available at https://authorea.com/users/410353/articles/519750-prognosticsignificance-of-monocyte-to-high-density-lipoprotein-ratio-in-patients-with-coronarychronic-total-occlusion

\section{Hosted file}

Table 3.pdf available at https://authorea.com/users/410353/articles/519750-prognosticsignificance-of-monocyte-to-high-density-lipoprotein-ratio-in-patients-with-coronarychronic-total-occlusion 

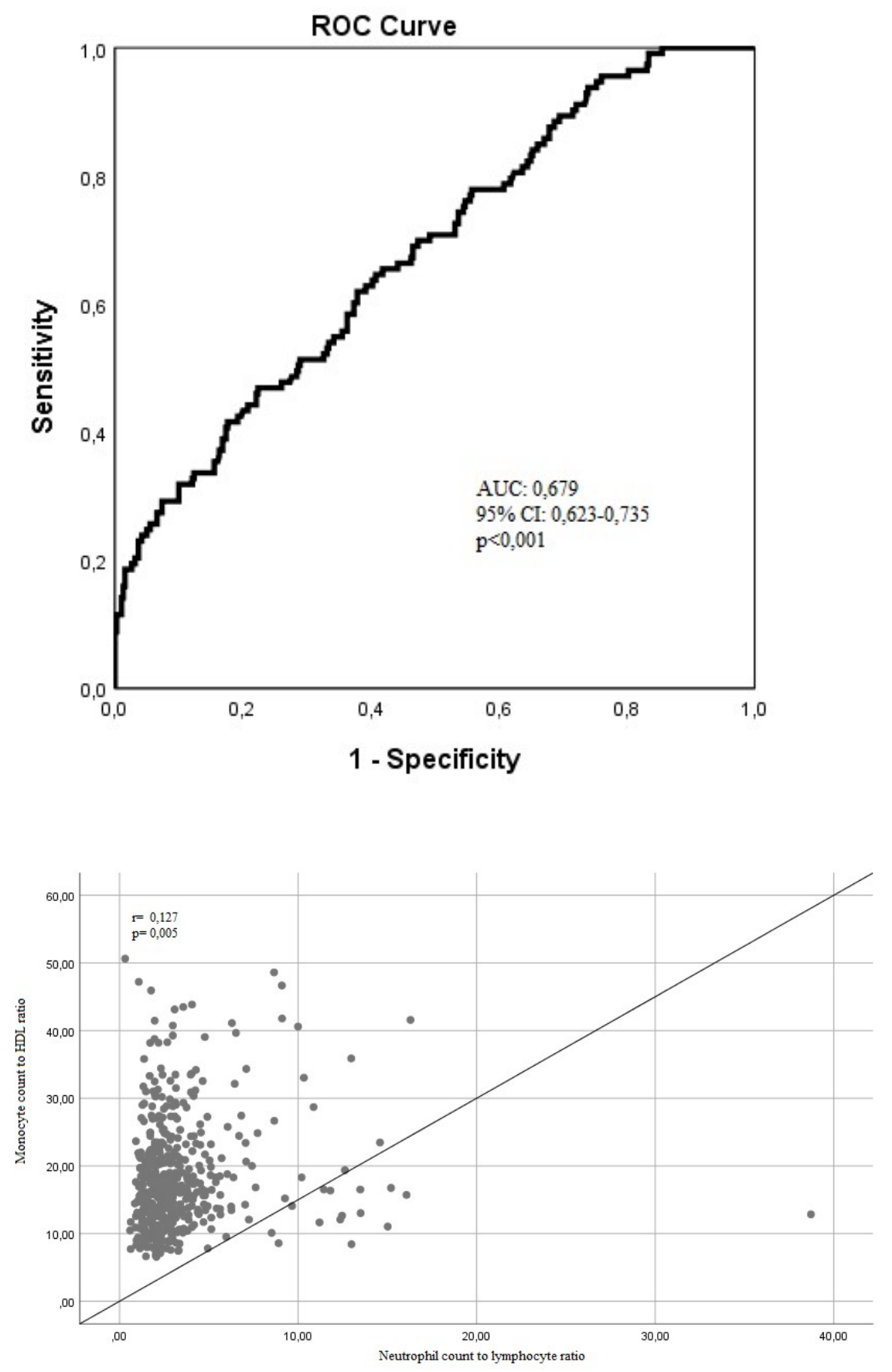


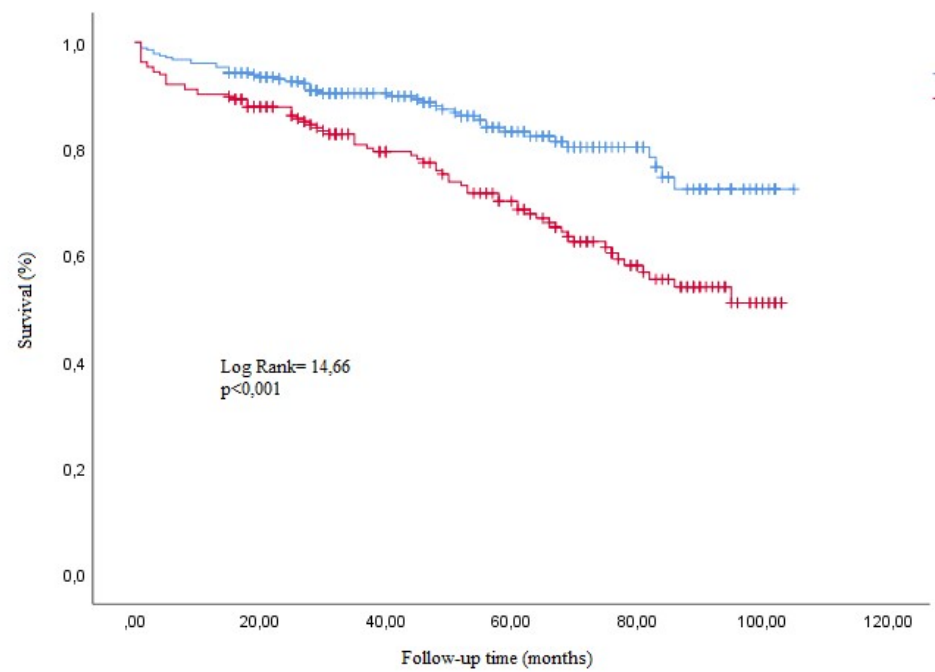

MHR $<17,6$

$\neg \quad \mathrm{MHR} \geq 17,68$ 